Article

\title{
Impact of Odor Nuisance on Preferred Place of Residence
}

\author{
Magdalena Wojnarowska ${ }^{1}\left(\mathbb{D}\right.$, Mariusz Sołtysik $^{2, *} \mathbb{C}$, Adam Sagan $^{3}$, Jadwiga Stobiecka ${ }^{3}$, \\ Jarosław Plichta ${ }^{4}$ and Grażyna Plichta ${ }^{3}$ \\ 1 Department of Technology and Ecology of Products, Cracow University of Economics, \\ 31-510 Cracow, Poland; wojnarom@uek.krakow.pl \\ 2 Management Process Department, Cracow University of Economics, 31-510 Cracow, Poland \\ 3 Department of Market Analysis and Marketing Research, Cracow University of Economics, \\ 31-510 Cracow, Poland; sagana@uek.krakow.pl (A.S.); jadwiga.stobiecka@uek.krakow.pl (J.S.); \\ plichtag@uek.krakow.pl (G.P.) \\ 4 Department of Trade and Market Institutions, Cracow University of Economics, 31-510 Cracow, Poland; \\ plichtaj@uek.krakow.pl \\ * Correspondence: soltysik@uek.krakow.pl
}

Received: 22 March 2020; Accepted: 9 April 2020; Published: 15 April 2020

check for updates

\begin{abstract}
Context of the research: Research is increasingly carried out to take into account the social behavior of residents, the type of industry located in the area, and perceived preference for the place of residence. The quality of life in urban space is increasingly seen as a problem of cooperation between various stakeholders. These studies not only identify factors and sources of odor emissions, but also serve as the basis for creating systems to alert people living in areas adjacent to industrial areas or harmful and unpleasant industrial emissions. In recent years, environmental issues, particularly unpleasant sensory experiences, have been one of the most important acceptance criteria. Aim of the article: The aim of the study is to assess the impact of odor nuisance in the south-eastern part of Kraków (Płaszów) on the residents' decision to leave their place of residence. In particular, the research goal was achieved to indicate which of the unpleasant odors may cause a change of residence, as well as to assess the degree of their impact on the decision to move, taking into account the social and demographic characteristics of residents. New in the article: The novelty of the work was the finding out of the residents' opinions about the quality of life by accepting the place of residence, taking into account the aspect of odor nuisance. Previous studies on odor nuisance have focused on the emission of odors from individual plants. A novelty of this research is its implementation in an urban area, in which numerous industrial plants are located, with various odors emitted. Research methodology: To assess odor nuisance, a measuring tool developed in accordance with VDI 3883 guidelines was used, based on the latest research results on odor and noise nuisance. The questionnaire was developed based on German experience. Conclusions from the research: The data obtained as a result of the research allow us to state that specific smells are so burdensome that they may cause the necessity to leave the place of residence, because the respondents feel various unpleasant smells that have an adverse impact upon the quality of life that they perceive. A possible need for relocation of domiciles out of the current place of residence due to unpleasant smells would affect the perceptible, specific level of grief-the greater it is, the more attached the residents are to their current place of residence.
\end{abstract}

Keywords: odor nuisance; preferred place of residence 


\section{Introduction}

Acceptance of domicile results from a variety of economic, environmental, ecological, and social factors. In recent years, environmental issues, particularly unpleasant sensory experiences, have been amongst the most important acceptance criteria. Fragrance is not the only component of the biological environment of man. There is also a cultural factor related to both the creation of fragrances as a result of human action and the impact upon interpersonal relationships ([1-3]). Numerous cross-sectional studies focus on fragrance ([4-6]) and identification of factors affecting the recognition and evaluation of fragrance by humans ([7]). Today, many authors see a link between fragrances, their emission sources, and the impact on people's quality of life, especially in the context of their place of residence [8-15]; and social relations [16-18] and economic relations [19].

A clear emphasis has been recently put on the issue of quality of life in cities from an ecological and sustainable development perspective, e.g., the impact and evaluation of quality of life in cities due to the existence of green spaces [20]. They increasingly refer to sustainability and smart city concepts [21]. Quality of life in urban space is also increasingly seen as a problem of cooperation among various stakeholders [22]. Therefore, it is extremely important to know and shape expectations and perceptions of residents regarding the quality of life by accepting the place of residence [23].

Research is increasingly being carried out to take into account the social behavior of residents, the type of industry located in the area [24], and the perceived preference toward domiciles [25]. Those studies not only identify the factors and sources of odor emissions, but also serve as the basis for creating systems to alert people living in areas adjacent to industrial sites or harmful and unpleasant industrial emissions [26].

Fragrances affect not only everyday life [27] and consumer decisions [28,29], but also health [30], the quality of work, and employees' health [31]. The presence of odor compounds in the ambient air is a serious problem, especially for residents of areas directly adjacent to municipal plants or an oasis of waste storage and processing plants. Fragrances can affect quality of life by causing symptoms associated with long-term exposure, including headaches, nausea, problems with concentration, loss of appetite, stress, insomnia, and discomfort. Fragrance irritation negatively affects the inhabitants of communities neighboring the persistent onerous industry [32]. Compared to other forms of air pollution, exposure to odor from human activities is generally considered to be burdensome and not a threat to public health or the environment. Characterization and odor measurement have become very important environmental issues due to the growing public awareness of the environment and the impact of air quality on health and well-being [33]. It is very important to know and shape the expectations and ideas of the inhabitants concerning the quality of life through the acceptance of the place of residence $[15,23,34-39]$.

Odor nuisance is one of the key problems, both on a local and national scale. This is due to the impact of odors on human behavior and quality of life [40]. The condition of the problem is confirmed by the growing number of complaints about odor nuisance. The source of odor formation can be plants in which animals are bred or waste is used, but also many other industries responsible for emissions, including hydrogen sulfide, ammonia, nitric oxide, aromatic hydrocarbons, sulfur compounds, aldehydes, to which the human nose is sensitive. Progressing urbanization results in reducing the distance between residential areas and municipal installations also generating odor nuisances. The range of odor impact usually does not exceed $200 \mathrm{~m}$. Apart from the distance from industrial plants, however, topographic and meteorological conditions are also important [41]. Odor reduction and control are currently serious problems for, among others, industrial plants that affect local society. This is one of the reasons for why fragrances are a growing problem, not only ecological but also social [42-44]

Scientific methods should bring social consensus combined with achieving environmental standards, especially since the control of odor emissions has become an important factor in the design of new investments at the stage of obtaining authorization. However, still, a significant problem is to solve the issue of odor nuisance from existing plants [45]. 
The results presented in the literature mainly concern the impact of odor nuisance on the quality of life of residents emitted by one industrial plant. The identified gap was the lack of research in urban areas with a large number of people in which industrial plants with different emission characteristics operate.

Taking into account the above thesis, a study was conducted in 2018 in Kraków, Poland, aimed at assessing the impact of odor nuisance in the context of the acceptance of the domicile. The aim of the paper is to assess the impact of odor nuisance in the south-eastern part of Kraków (Płaszów) on the decision of residents to leave their place of residence. In particular, the research objective was achieved in order to to indicate which of the unpleasant smells may cause a change in place of residence as well as to assess the degrees of their impact on the decision to move out, taking into account the social and demographic characteristics of the residents.

The main research hypothesis was formulated: Odor nuisance may influence the decision to leave the place of residence by the inhabitants of Płaszów. The following detailed hypotheses were formulated:

Hypothesis 1. Odor nuisance affects the decision of residents to leave their place of residence.

Hypothesis 2. There is a relationship between the degree of unpleasant septic tank smell felt by the residents, the decision to relocate one's domicile out of the existing apartment, and the regret caused by this decision.

Hypothesis 3. There is a correlation between the decision to relocate one's domicile out and the age of the respondents.

Hypothesis 4. Gender influences the perceived type of nuisance that could cause a person to leave the domicile and the level of grief caused by this decision.

Hypothesis 5. The duration of stay in the place of residence determines the perception of smells having an adverse impact on the quality of life.

\section{Materials and Methods}

\subsection{Framework of Studies}

The presence of fragrance in the ambient air is a serious problem, especially for the inhabitants of areas directly adjacent to municipal plants $[46,47]$ and solid waste disposal or wastewater treatment plants. Fragrance compounds may cause deterioration of quality of life, causing symptoms associated with long-term exposure, including headaches, nausea, concentration problems, loss of appetite, stress, insomnia, and discomfort, which indirectly translates into a desire to stay at a given location [32]. Compared with other forms of air pollution, exposure to odor resulting from human activities is generally considered a nuisance rather than a threat to public health or the environment, as opposed to noise pollution, the measurement, regulation, and effects of which on human health are well known [25,48-51].

The literature describes the methods used to measure odor in detail. One of the methods used to test odor nuisance is field olfactometry, which allows the determination of the level of odor nuisance, but not its composition. To this end, other methods should be used to enable detailed characterization in terms of both composition and concentration of fragrances [52]. The oldest and most consolidated method of characterizing fragrances is based on the use of analytical techniques to identify and quantify fragrances. The main method is gas chromatography supported by mass spectrometry. On-site measurements are usually made using mobile laboratories. Devices supporting odor testing are particularly important where measurement using human smell is dangerous or impossible to carry out. Therefore, in recent years, an increase in odor tests using devices called electronic noses can be 
seen $[47,53]$, i.e., devices that function as an equivalent of the human sense of smell [54]. The proposed tests supplement the mentioned tests. They are in the exploratory stage and show the legitimacy of using cost-intensive research.

The issue of odor nuisance is not governed by law in Poland; there are no standards and procedures, so it is often difficult to determine even such an important issue as who is to deal with the issue of odor nuisance, i.e., which governmental institution is responsible for monitoring the environment to this end. Moreover, the location policy is not governed by law either, which means that industrial areas are located near residential areas. Some districts in Kraków exemplify that. The research was conducted in the south-eastern part of Kraków (Płaszów). This region is characterized by the highest growth of urbanized areas and changes in the spatial development of the areas of the municipality of Kraków. They have the largest number of industrial plants, including the largest sewage treatment plant in the Małopolskie (Small Poland) Province (Voivodeship). Odor problems were a major problem for the residents of Płaszów, and they often reported these institutions to monitor environmental protection.

\subsection{Methodological Assumptions}

The research process included the stage of diagnosis and identification of the research problem. The analysis was conducted on the basis of a systematic review of literature and analysis of internet forums in closed groups on Facebook, in which residents of the Płaszów district in Krakow speak. A total of 716 comments were posted in which the subject of bothersome odors in the Płaszów area was raised. The analysis of content also drew attention to the complaints of residents affecting everyday life and resulting from the onerous odors. Then, research goals and hypotheses were formulated. Based on the experience of German and international odor and noise research, a questionnaire was developed based on the VDI 3883 standard [55-58]. The prepared questionnaire allowed us to conduct research in the Płaszów district of Krakow. The questions in the questionnaire reflected the research questions. The most important part of the questionnaire included the questions scaled on two nuisance scales, i.e., a seven-degree ordinal scale and ten-point interval scale. They made it possible to collect information from respondents significantly related to the purpose of the study.

The surveyed population consisted of respondents representing households located in the Płaszów region. The research sample consisted of respondents representing households using water supply and sewage treatment services located in the Płaszów region. In this area, according to the data obtained, 21,925 people use these services. Taking into account the limited access to respondents and their reluctance to participate in the survey, the sample size was finally accepted to include 2000 questionnaires. After collecting the data and carrying out a preliminary verification, 1992 correctly completed questionnaires were qualified for the analysis purposes. The least favorable structure indicator $(50 \%)$ accounts for an estimation error at $2.09 \%$. This result is satisfactory and the sample size is within the typical sample sizes used for social research purposes.

\subsection{Data Analysis Methods}

The variety of perceived odors is coded on a binary scale (0-1). The introductory analysis of the relationships between perceived odors and socio-demographic characteristics of inhabitants was based on rank-order Spearman correlation coefficients. The strength of correlation was interpreted according to the following scheme [59]:

$|\mathrm{r}| \geq 0.9$-very strong correlation,

$0.7 \leq|\mathrm{r}|<0.9$-strong correlation,

$0.5 \leq|\mathrm{r}|<0.7-$ medium strong correlation,

$0.3 \leq|\mathrm{r}|<0.5$-weak correlation,

$|\mathrm{r}|<0.3$-very weak correlation (negligible). 
An analysis of correspondence was performed in order to obtain a bi-plot presenting the correlation among variables. The analysis was conducted by means of $\mathrm{R}$ software, version 3.6.1 [60]. All $p$-values below 0.05 were interpreted to prove significant correlations.

The reduction of odor variety and identification of latent odor dimensions was carried out by means of multiple correspondence analyses (MCA) and, specifically, the HOMALS algorithm. The application of MCA enabled the identification of the latent continuum of odor dimensions (as respondents' coordinates) and used them as explanatory factors for multiple regression. Three dimensions were singled out on their basis. Further analyses were performed by means of regression analysis.

In multiple regression analysis, regret for leaving the apartment was used as the dependent variable, and orthogonal dimensions of odor (as a result of MCA) as independent variables. Several socio-demographic characteristics (gender, age, life expectancy in the town, life expectancy in the place of residence, and life expectancy in the current domicile) were used as moderator variables. Additionally, the plots of interaction effects for all of the interactions were added.

\subsection{Sample Characteristics}

The quantitative survey covered 1992 respondents, $58.56 \%$ of whom were women and $41.44 \%$ men. People aged from 18 to 90 years were included in the study. The average age of respondents was 39 years old (age distribution is characterized by normal distribution). Over $50 \%$ of the respondents declared higher education $(50.76 \%)$, higher bachelor/engineer education $(16.28 \%)$, and secondary education $(27.24 \%)$. Only $5.72 \%$ of people were respondents with lower secondary education (i.e., primary, lower secondary, vocational). A total of $78.96 \%$ of the respondents were married, while only $21.04 \%$ of the whole sample declared their marital status as being single. In terms of the data obtained, it bears noting that the vast majority of respondents did not declare their involvement in the affairs of any local organization or association. Only $2.76 \%$ of respondents declared active involvement in the operations of social organizations, while just over $10.89 \%$ declared passive involvement.

The results of the research indicate that the area (neighborhood) is mostly inhabited by people who have settled over the last 20 years. They account for nearly $75 \%$ of the population (upper quartile). Approximately $25 \%$ of the residents declared that they had settled in the last four years (lower quartile), which indicates that the average residence in the area for all respondents is durable for 15 years.

\section{Research Results}

\subsection{In General}

Unpleasant odor may, in extreme cases, make it impossible to stay in the affected area. As a result, inhabitants of such areas may be forced to change their places of living. Some people, especially those who are particularly attached to their current place of residence, may feel a certain level of regret because of this. As the compiled data indicate (Table 1), the grief resulting from a possible domicile relocation correlates significantly and positively with the odor emitted by septic tanks (as $p<0.05$ ), so the more frequently these smells are mentioned, the greater the grief felt over domicile relocation may be. The regret about a possible domicile relocation correlates significantly and negatively with the smell described as decay (because $p<0.05$ ), so the more often these smells are mentioned, the lesser regret due to a possible domicile relocation. 
Table 1. Correlation with the regret about a possible domicile relocation-in general.

\begin{tabular}{ccccc}
\hline $\begin{array}{c}\text { Description of } \\
\text { Odor }\end{array}$ & \multicolumn{2}{c}{ Correlation with the Regret about a Possible Domicile Relocation } \\
& Correlation Coefficient* & $p$ & $\begin{array}{c}\text { Direction of } \\
\text { Correlation }\end{array}$ & $\begin{array}{c}\text { Strength of } \\
\text { Correlation }\end{array}$ \\
\hline Chemical & 0.031 & $p=0.239$ & - & - \\
Irritating & -0.023 & $p=0.384$ & - & - \\
Suffocating & -0.037 & $p=0.157$ & - & - \\
Smoke & 0 & $p=0.993$ & - & - \\
Sharp & -0.032 & $p=0.225$ & - & - \\
Sulfur & 0.03 & $p=0.25$ & - & - \\
Sweet & 0.019 & $p=0.469$ & - & - \\
Burnt & -0.05 & $p=0.06$ & very weak \\
Exhaust & -0.014 & $p=0.59$ & - \\
Septic tank & 0.062 & $p=0.018$ & positive & - \\
Garbage & -0.009 & $p=0.737$ & negative & very weak \\
Rot & -0.067 & $p=0.012$ & neak \\
Rotten eggs & 0.002 & $p=0.936$ & - & - \\
\hline
\end{tabular}

* Spearman's correlation coefficient. Source: Authors' calculations.

\subsubsection{Age of Respondents and Feeling Sorry for the Necessity to Change Their Place of Residence}

Taking into account the social and demographic data of respondents, in the first stage of the analysis, the impact of the age of respondents on the statements concerning the level of regret resulting from the necessity to decide whether to move out of the place of residence due to unpleasant smells was assessed. The compiled data were divided according to the median, which resulted in two more or less similar equilibrium groups of respondents differing in age. In the case of respondents aged up to 36 years, regret about a possible domicile relocation (Table 2) correlates significantly and positively with the smells emitted by septic tanks (as $p<0.05$ ), so the more often these smells are mentioned, the greater regret about a possible domicile relocation. The regret about a possible domicile relocation correlates significantly and negatively with the smells emitted by burning (because $p<0.05$ ), so the more often these smells are mentioned, the less regret is caused by possible domicile relocation.

Table 2. Correlation with the regret about a possible domicile relocation-below 36 years of age.

\begin{tabular}{|c|c|c|c|c|}
\hline \multirow[b]{2}{*}{$\begin{array}{l}\text { Description of } \\
\text { odor }\end{array}$} & \multicolumn{4}{|c|}{ Correlation with the Regret about a Possible Domicile Relocation } \\
\hline & Correlation Coefficient* & $p$ & $\begin{array}{l}\text { Direction of } \\
\text { Correlation }\end{array}$ & $\begin{array}{l}\text { Strength of } \\
\text { Correlation }\end{array}$ \\
\hline Chemical & -0.006 & $p=0.859$ & - & - \\
\hline Irritating & -0.039 & $p=0.288$ & - & - \\
\hline Suffocating & -0.039 & $p=0.281$ & - & - \\
\hline Smoke & -0.053 & $p=0.144$ & - & - \\
\hline Sharp & 0.023 & $p=0.522$ & - & - \\
\hline Sulfur & 0.016 & $p=0.669$ & - & - \\
\hline Sweet & 0.034 & $p=0.354$ & - & - \\
\hline Burnt & -0.149 & $p<0.001$ & negative & very weak \\
\hline Exhaust & -0.065 & $p=0.073$ & - & - \\
\hline Septic tank & 0.106 & $p=0.004$ & positive & very weak \\
\hline Garbage & 0.018 & $p=0.631$ & - & - \\
\hline Rot & -0.007 & $p=0.847$ & - & - \\
\hline Rotten eggs & 0.007 & $p=0.846$ & - & - \\
\hline
\end{tabular}

* Spearman's correlation coefficient. Source: Authors' calculations. 


\subsubsection{Over 36 Years of Age}

In the case of respondents over 36 years of age, the grief felt over a possible domicile relocation correlates significantly and negatively with odors (Table 3) described as acute or the smell of rot (as $p<0.05$ ), so the more frequently such an odor is mentioned, the less regret about a possible domicile relocation.

Table 3. Correlation with the regret about a possible domicile relocation-over 36 years of age.

\begin{tabular}{|c|c|c|c|c|}
\hline \multirow[b]{2}{*}{$\begin{array}{l}\text { Description of } \\
\text { Odor }\end{array}$} & \multicolumn{4}{|c|}{ Correlation with the Regret about a Possible Domicile Relocation } \\
\hline & Correlation Coefficient ${ }^{*}$ & $p$ & $\begin{array}{l}\text { Direction of } \\
\text { Correlation }\end{array}$ & $\begin{array}{l}\text { Strength of } \\
\text { Correlation }\end{array}$ \\
\hline Chemical & 0.067 & $p=0.078$ & - & - \\
\hline Irritating & -0.008 & $p=0.835$ & - & - \\
\hline Suffocating & -0.034 & $p=0.373$ & - & - \\
\hline Smoke & 0.049 & $p=0.199$ & - & - \\
\hline Sharp & -0.084 & $p=0.027$ & negative & very weak \\
\hline Sulfur & 0.065 & $p=0.089$ & - & - \\
\hline Sweet & 0.008 & $p=0.825$ & - & - \\
\hline Burnt & 0.032 & $p=0.404$ & - & - \\
\hline Exhaust & 0.034 & $p=0.38$ & - & - \\
\hline Septic tank & 0.022 & $p=0.557$ & - & - \\
\hline Garbage & -0.059 & $p=0.124$ & - & - \\
\hline Rot & -0.127 & $p=0.001$ & negative & very weak \\
\hline Rotten eggs & -0.003 & $p=0.93$ & - & - \\
\hline
\end{tabular}

* Spearman's correlation coefficient. Source: Authors' calculations.

\subsection{Sex and Smell Related to the Regret about Leaving the Place of Residence}

In the next stage of the analysis, the relationship between gender and the emotional approach to the necessity of a possible move out of the place of residence, i.e., regret resulting from this decision, was evaluated. In the case of women (Table 4), regret caused by a possible domicile relocation correlates significantly and positively with the smells described as sulfur (because $p<0.05$ ), so the more often these smells are mentioned, the greater regret caused by a possible domicile relocation. The regret about a possible domicile relocation correlates significantly and negatively with the smells described as burning (because $p<0.05$ ), so the more often these smells are mentioned, the lesser regret about a possible domicile relocation.

Table 4. Correlation with the regret about a possible domicile relocation-women.

\begin{tabular}{|c|c|c|c|c|}
\hline \multirow[b]{2}{*}{$\begin{array}{l}\text { Description of } \\
\text { odor }\end{array}$} & \multicolumn{4}{|c|}{ Correlation with the Regret about a Possible Domicile Relocation } \\
\hline & Correlation Coefficient ${ }^{*}$ & $p$ & $\begin{array}{l}\text { Direction of } \\
\text { Correlation }\end{array}$ & $\begin{array}{l}\text { Strength of } \\
\text { Correlation }\end{array}$ \\
\hline Chemical & 0.065 & $p=0.059$ & - & - \\
\hline Irritating & 0.017 & $p=0.62$ & - & - \\
\hline Suffocating & -0.042 & $p=0.226$ & - & - \\
\hline Smoke & -0.002 & $p=0.962$ & - & - \\
\hline Sharp & -0.011 & $p=0.739$ & - & - \\
\hline Sulfur & 0.075 & $p=0.028$ & positive & very weak \\
\hline Sweet & 0.015 & $p=0.665$ & - & - \\
\hline Burnt & -0.091 & $p=0.008$ & negative & very weak \\
\hline Exhaust & -0.03 & $p=0.376$ & - & - \\
\hline Septic tank & 0.052 & $p=0.132$ & - & - \\
\hline Garbage & -0.015 & $p=0.671$ & - & - \\
\hline Rot & -0.054 & $p=0.118$ & - & - \\
\hline Rotten eggs & 0.004 & $p=0.918$ & - & - \\
\hline
\end{tabular}

* Spearman's correlation coefficient. Source: Authors' calculations. 
In the case of men (Table 5), the regret about a possible domicile relocation correlates significantly and positively with the smells emitted by septic tanks (as $p<0.05$ ), so the more frequently those smells are mentioned, the greater the regret about a possible domicile relocation. The regret about a possible domicile relocation correlates significantly and negatively with the smells described as rotten or irritating (because $p<0.05$ ), so the more often these smells are mentioned, the less regret about a possible domicile relocation.

Table 5. Correlation with the regret about a possible domicile relocation-men.

\begin{tabular}{ccccc}
\hline $\begin{array}{c}\text { Description of } \\
\text { odor }\end{array}$ & $\begin{array}{c}\text { Correlation with the Regret about a Possible Domicile Relocation } \\
\text { Direction of } \\
\text { Correlation }\end{array}$ & $\begin{array}{c}\text { Strength of } \\
\text { Correlation }\end{array}$ \\
\hline Chemical & -0.019 & $p$ & - & - \\
Irritating & -0.086 & $p=0.64$ & negative & very weak \\
Suffocating & -0.038 & $p=0.361$ & - & - \\
Smoke & 0.01 & $p=0.811$ & - & - \\
Sharp & -0.061 & $p=0.139$ & - & - \\
Sulfur & -0.068 & $p=0.097$ & - & - \\
Sweet & 0.024 & $p=0.568$ & - & - \\
Burnt & 0.023 & $p=0.583$ & - & - \\
Exhaust & 0.011 & $p=0.79$ & - & very weak \\
Septic tank & 0.082 & $p=0.048$ & positive & - \\
Garbage & 0.004 & $p=0.914$ & - & very weak \\
Rot & -0.085 & $p=0.041$ & negative & - \\
Rotten eggs & 0.012 & $p=0.78$ & - & - \\
\hline
\end{tabular}

* Spearman's correlation coefficient. Source: Own calculations.

\subsection{Influence of Fragrances on Attitudes of People Up to 25 Years of Age}

In the next stage, the impact of the period of residence in Kraków on the regret resulting from the necessity of possible moving out of the current place of residence under the influence of unpleasant smells was assessed. A division was made of the variable in relation to the median, resulting in two more or less similar equilibrium groups of respondents differing in this period. In the case of respondents of up to 25 years of age living in Kraków (Table 6), the regret about a possible domicile relocation correlates significantly and positively with the smells emitted by septic tanks (as $p<0.05$ ), so the more frequently these smells are mentioned, the greater the regret about a possible domicile relocation. The regret about a possible domicile relocation correlates significantly and negatively with the smells described as burning (as $p<0.05$ ), so the more often these smells are mentioned, the less regret about a possible domicile relocation.

Table 6. Correlation with the regret about a possible domicile relocation-25 years of age.

\begin{tabular}{ccccc}
\hline $\begin{array}{c}\text { Description of } \\
\text { odor }\end{array}$ & $\begin{array}{c}\text { Correlation with the Regret about a Possible Domicile Relocation } \\
\text { Direction of } \\
\text { Correlation }\end{array}$ & $\begin{array}{c}\text { Strength of } \\
\text { Correlation }\end{array}$ \\
\hline Chemical & 0.019 & $p$ & - & - \\
Irritating & -0.02 & $p=0.599$ & - & - \\
Suffocating & -0.028 & $p=0.453$ & - & - \\
Smoke & -0.046 & $p=0.208$ & - & - \\
Sharp & -0.054 & $p=0.145$ & - & - \\
Sulfur & 0.002 & $p=0.953$ & - & - \\
Sweet & 0.033 & $p=0.372$ & - & very weak \\
Burnt & -0.159 & $p<0.001$ & negative & - \\
Exhaust & 0.005 & $p=0.891$ & - & very weak \\
Septic tank & 0.098 & $p=0.008$ & positive & - \\
Garbage & 0.032 & $p=0.382$ & - & - \\
Rot & -0.009 & $p=0.8$ & - & - \\
Rotten eggs & -0.028 & $p=0.455$ & - & \\
\hline
\end{tabular}

* Spearman's correlation coefficient. Source: Authors' calculations. 


\subsection{Residing in Kraków for More than 25 Years}

In the case of residents staying in the city for over 25 years (Table 7), the regret about a possible domicile relocation correlates significantly and positively with the smells described as sulfur (because $p<0.05)$, so the more frequently those smells are mentioned, the greater the regret about a possible domicile relocation. The regret about a possible domicile relocation correlates significantly and negatively with the smells described as decay $(p<0.05)$, so the more often these smells are mentioned, the less the regret about a possible domicile relocation.

Table 7. Correlation with the regret about a possible domicile relocation-over 25 years of age.

\begin{tabular}{ccccc}
\hline Odor Description & \multicolumn{2}{c}{ Correlation with the Regret about a Possible Domicile Relocation } \\
& Correlation Coefficient & $p$ & $\begin{array}{c}\text { Direction of } \\
\text { Correlation }\end{array}$ & $\begin{array}{c}\text { Strength of } \\
\text { Correlation }\end{array}$ \\
\hline Chemical & 0.039 & $p=0.311$ & - & - \\
Irritating & -0.021 & $p=0.576$ & - & - \\
Suffocating & -0.048 & $p=0.212$ & - & - \\
Smoke & 0.028 & $p=0.471$ & - & - \\
Sharp & -0.02 & $p=0.603$ & - & - \\
Sulfur & 0.079 & $p=0.039$ & positive & very weak \\
Sweet & 0.002 & $p=0.967$ & - & - \\
Burning & 0.034 & $p=0.378$ & - & - \\
Exhaust & -0.047 & $p=0.217$ & - & - \\
Septic tank & 0.029 & $p=0.443$ & - & - \\
Garbage & -0.058 & $p=0.131$ & - & very weak \\
Rot & -0.124 & $p=0.001$ & negative & - \\
Rotten eggs & 0.045 & $p=0.24$ & - & - \\
\hline
\end{tabular}

* Spearman's correlation coefficient. Source: Authors' calculations.

\subsection{The Period of Residence and the Regret Caused by the Necessity to Leave the Place of Residence Due to Smells}

In the next stage, the statements of people living in the area were evaluated. In the case of those who have been living there for less than 10 years (median criterion-Table 8), the regret about a possible domicile relocation correlates significantly and positively with the smells emitted by septic tanks (because $p<0.05$ ), so the more often these smells are mentioned, the greater the regret about a possible domicile relocation. The regret about a possible domicile relocation correlates significantly and negatively with the smells described as burning or irritating (because $p<0.05$ ), so the more often these smells are mentioned, the less regret is caused by a possible domicile relocation.

Table 8. Correlation with regret about possible domicile relocation-up to 10 years.

\begin{tabular}{ccccc}
\hline Odor Description & \multicolumn{3}{c}{ Correlation with the Regret about a Possible Domicile Relocation } \\
Direction of & $\begin{array}{c}\text { Strength of } \\
\text { Correlation }\end{array}$ & Correlation \\
\hline Chemical & 0.031 & $p$ & - & - \\
Irritating & -0.079 & $p=0.402$ & negative & very weak \\
Suffocating & -0.07 & $p=0.031$ & - & - \\
Smoke & 0.021 & $p=0.055$ & - & - \\
Sharp & -0.038 & $p=0.568$ & - & - \\
Sulfur & -0.017 & $p=0.294$ & - & - \\
Sweet & 0.044 & $p=0.633$ & negative & very weak \\
Burnt & -0.115 & $p=0.225$ & - & - \\
Exhaust & 0.012 & $p=0.743$ & positive & very weak \\
Septic tank & 0.114 & $p=0.002$ & - & - \\
Garbage & -0.007 & $p=0.846$ & - & - \\
Rot & -0.049 & $p=0.178$ & - & - \\
Rotten eggs & -0.025 & $p=0.485$ & -
\end{tabular}

* Spearman's correlation coefficient. Source: Authors' calculations. 
In the case of subjects living in the area for more than 10 years (Table 9), the regret about a possible domicile relocation correlates significantly and positively with the smells described as sulfur (because $p<0.05)$, so the more frequently these smells are mentioned, the greater the regret about a possible domicile relocation.

Table 9. Correlation with the regret about possible domicile relocation-over 10 years.

\begin{tabular}{ccccc}
\hline $\begin{array}{c}\text { Description of } \\
\text { odor }\end{array}$ & \multicolumn{2}{c}{ Correlation with the Regret about a Possible Domicile Relocation } \\
Direction of & $\begin{array}{c}\text { Strength } \\
\text { Correlation }\end{array}$ & Correlation \\
\hline Chemical & 0.021 & $p$ & $p=0.603$ & - \\
Irritating & 0.039 & $p=0.321$ & - & - \\
Suffocating & -0.009 & $p=0.814$ & - & - \\
Smoke & -0.028 & $p=0.475$ & - & - \\
Sharp & -0.014 & $p=0.716$ & - & - \\
Sulfur & 0.091 & $p=0.022$ & positive & very weak \\
Sweet & -0.014 & $p=0.731$ & - & - \\
Burnt & -0.012 & $p=0.757$ & - & - \\
Exhaust & -0.051 & $p=0.203$ & - & - \\
Septic tank & 0.041 & $p=0.307$ & - & - \\
Garbage & 0.008 & $p=0.841$ & - & - \\
Rot & -0.065 & $p=0.103$ & - & - \\
Rotten eggs & 0.041 & $p=0.304$ & - & - \\
\hline
\end{tabular}

* Spearman's correlation coefficient. Source: Authors' calculations.

Multiple correspondence analyses revealed three main dimensions of fragrance. The graph of eigenvalues is shown in Figure 1.

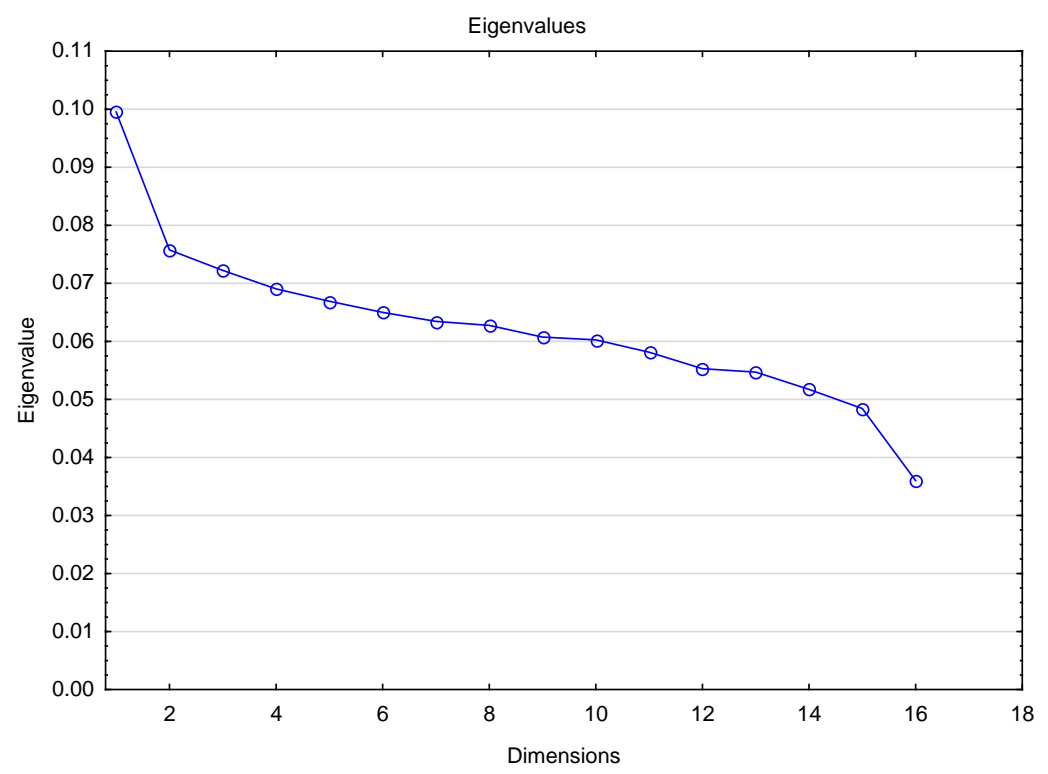

Figure 1. Multiple correspondence analysis.

The first three dimensions explain $23 \%$ of the total inertia of Table 10 of the data. Based on the inertia input and cosine squares (see table), the following odor dimensions were distinguished: Dimension 1 (combustion, automobile exhaust, rot,), dimension 2 (rubbish, carrion, irritating), and dimension 3 (smoke, suffocation, rotten eggs). 
Table 10. Odor dimensions.

\begin{tabular}{ccccccc}
\hline Fragrances & $\begin{array}{c}\text { Inertia } \\
\text { Dimension1 }\end{array}$ & $\begin{array}{c}\text { Cos }^{2} \\
\text { Dimension1 }\end{array}$ & $\begin{array}{c}\text { Inertia } \\
\text { Dimension2 }\end{array}$ & $\begin{array}{c}\text { Cos }^{2} \\
\text { Dimension2 }\end{array}$ & $\begin{array}{c}\text { Inertia } \\
\text { Dimension3 }\end{array}$ & $\begin{array}{c}\text { Cos }^{2} \\
\text { Dimension3 }\end{array}$ \\
\hline Chemical & 0.014324 & 0.075608 & 0.107465 & 0.026238 & 0.035559 & 0.007671 \\
\hline Irritating & 0.003576 & 0.007104 & 0.093865 & 0.141931 & 0.033290 & 0.047996 \\
\hline Suffocating & 0.000546 & 0.000877 & 0.006078 & 0.007424 & 0.129469 & 0.150780 \\
\hline Smoke & 0.011870 & 0.019343 & 0.075914 & 0.094160 & 0.244721 & 0.289424 \\
\hline Nauseating & 0.009070 & 0.014509 & 0.002737 & 0.003332 & 0.004947 & 0.005743 \\
\hline Sharp & 0.000377 & 0.000648 & 0.020880 & 0.027311 & 0.040736 & 0.050804 \\
\hline Carrion & 0.003723 & 0.005945 & 0.272348 & 0.330960 & 0.009593 & 0.011116 \\
\hline Palk & 0.003858 & 0.006156 & 0.000816 & 0.000991 & 0.002596 & 0.003006 \\
\hline Sulfur & 0.002936 & 0.004705 & 0.011926 & 0.014547 & 0.017715 & 0.020605 \\
\hline Sweet & 0.000182 & 0.000303 & 0.002999 & 0.003804 & 0.069472 & 0.084009 \\
\hline Burning & 0.193384 & 0.420641 & 0.000739 & 0.001224 & 0.016623 & 0.026241 \\
\hline Sams & 0.199981 & 0.381934 & 0.000452 & 0.000657 & 0.050861 & 0.070495 \\
\hline Septic tank & 0.092586 & 0.415320 & 0.005281 & 0.018032 & 0.001133 & 0.003689 \\
\hline Garbage & 0.018859 & 0.030733 & 0.326387 & 0.404834 & 0.005246 & 0.006204 \\
\hline Rot & 0.116180 & 0.268953 & 0.000214 & 0.000377 & 0.032383 & 0.054406 \\
\hline Eggs & 0.000655 & 0.001057 & 0.044819 & 0.055092 & 0.252288 & 0.295697 \\
\hline
\end{tabular}

Separate dimensions of fragrances were variables explaining the regret about possible moving in the model of moderated regression (dimensions and regret were standardised variables with the mean $=0$ and variance $=1$ ). The moderating variables of the influence of smell on grief were sex, age, and length of residence in Cracow, in the vicinity and in the apartment.

In the first two-group regression model, between the dimensions of smells and regret for leaving the apartment (Table 11), the smells of burning and smoke turned out to be important dimensions of smell among women. The smell of burning reduced the grief of leaving the apartment due to the nuisance of smell, while the dimension of smoke added to the grief of leaving the apartment. Among men, no dimension significantly affected the regret for leaving the apartment.

Table 11. Two-group regression model—smell and regret about leaving the place of residence.

\begin{tabular}{ccccc}
\hline Parameters & Estimate & S.E. & Est/S.E. & $p$-Value \\
\hline & \multicolumn{5}{c}{ Females } \\
Regret on Burning & -0.191 & 0.095 & -2.013 & $0.044^{*}$ \\
Regret on Irritating & 0.068 & 0.100 & 0.679 & 0.497 \\
Regret on Smoke & 0.231 & 0.111 & 2.081 & $0.037^{*}$ \\
Residual Regret & 0.991 & 0.046 & 31.579 & $0.000^{*}$ \\
& \multicolumn{5}{c}{} \\
Regret on Burning & 0.110 & Males & 0.065 \\
Regret on Irritating & -0.227 & 0.587 & 0.557 & 0.147 \\
Regret on Smoke & -0.170 & 0.130 & -1.452 & 0.191 \\
Residual Regret & 0.997 & 0.035 & -1.308 & $0.000^{*}$ \\
\hline \multicolumn{5}{c}{ parameters significant at $\alpha<0.05}$.
\end{tabular}

The independent variables (burning, irritating, and smoke) are the result of multiple correspondence analysis (HOMALS algorithm) of qualitative indicators; therefore, they are mutually orthogonal. The Adjusted $\mathrm{R}^{2}$ of Regret is very low and equals 0.003 for the male group and 0.006 for the female group. The tolerance (collinearity measure) for independent variables for the male group is 
between 0.998 and 0.999 and, for the female group, is between 0.997 and 0.999 . The assumption of non-collinearity is valid.

The following models are the models with moderation effects of three independent dimensions of odors with social-demographic variables (age, life expectancy in the city, period of residence in the housing estate, and life expectancy of the current domicile). In order to partially control the collinearity between interacting independent variables, the original variables were centered.

The second model determines the relationship between grief and smell dimensions, taking into account the effect of moderation in the age section (Table 12).

Table 12. Two-group regression model—regret and odor dimensions, taking into account the effect of moderation in the age cross-section.

\begin{tabular}{ccccc}
\hline Parameters & Estimate & S.E. & Est/S.E. & $p$-Value \\
\hline Regret on Age & 0.001 & 0.002 & 0.270 & 0.787 \\
Regret on Burning & -1.015 & 0.254 & -3.999 & $0.000^{*}$ \\
Regret on Irritating & 0.258 & 0.338 & 0.764 & 0.445 \\
Regret on Smoke & -0.092 & 0.275 & -0.335 & 0.738 \\
Regret on Burning x Age & 0.023 & 0.006 & 3.761 & $0.000^{*}$ \\
Regret on Irritating x Age & -0.007 & 0.009 & -0.825 & 0.409 \\
Regret on Smoke x Age & 0.005 & 0.007 & 0.637 & 0.524 \\
Residual Regret & 0.998 & 0.035 & 28.136 & $0.000^{*}$ \\
\hline
\end{tabular}

* parameters significant at $\alpha<0.05$. The $\mathrm{R}^{2}$ for this model equals 0.011 .

In this model, there was a negative influence of the smell of burning on the grief of leaving the place of residence, but a significant positive influence of the interaction of age and dimension of the smell of burning on the feeling of grief.

The diagram of the effect of age moderation on the burning dimension is presented in Figure 2.

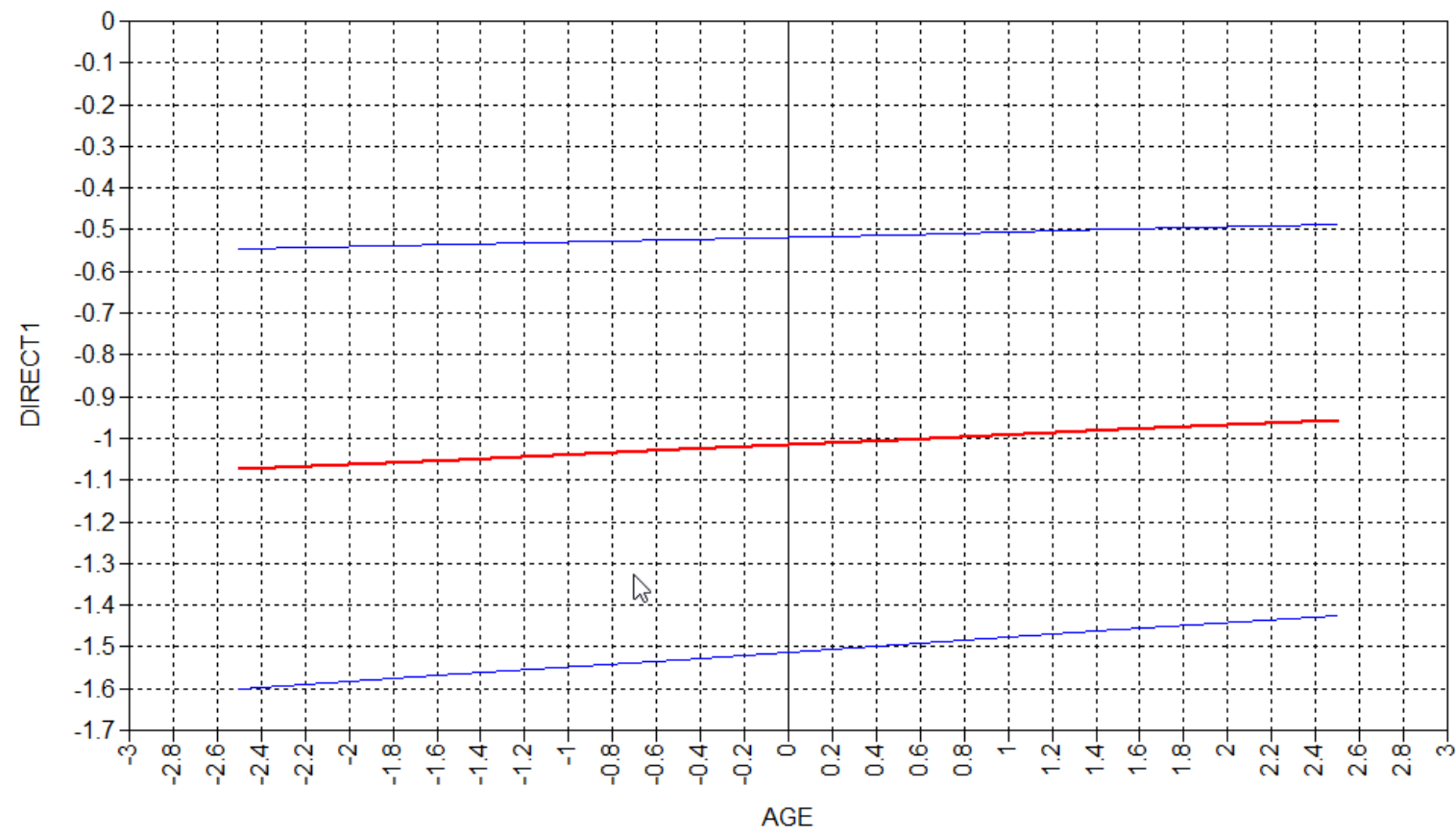

Figure 2. Age moderation effect vs. burning dimension.

The graph shows that the lower and upper confidence limits of the parameter do not contain the zero value of the moderation effect. It is claimed that there is a positive effect of interaction-with the increase in age of the respondents, there is a stronger positive effect of the burning dimension on the grief of leaving the apartment. 
The third model concerns the relationship between grief and smell dimensions, taking into account the moderation effect in the cross-section of life expectancy in the city (Table 13).

Table 13. Relationship between regret and smell dimensions, taking into account the moderation effect in the cross-section of life expectancy in the city.

\begin{tabular}{ccccc}
\hline Parameters & Estimate & S.E. & Est/S.E. & $p$-Value \\
\hline Regret on Town & 0.004 & 0.001 & 2.677 & $0.007^{*}$ \\
Regret on Burning & -0.643 & 0.136 & -4.714 & $0.000^{*}$ \\
Regret on Irritating & 0.155 & 0.160 & 0.970 & 0.332 \\
Regret on Smoke & -0.132 & 0.156 & -0.844 & 0.399 \\
Regret on Burning x Town & 0.019 & 0.004 & 4.554 & $0.000^{*}$ \\
Regret on Irritating x Town & -0.007 & 0.005 & -1.265 & 0.206 \\
Regret on Smoke x Town & 0.007 & 0.005 & 1.525 & 0.127 \\
Residual Regret & 0.978 & 0.035 & 28.134 & $0.000^{*}$ \\
\hline
\end{tabular}

* parameters significant at $\alpha<0.05$. The $\mathrm{R}^{2}$ for this model equals 0.021 .

The parameters of the model indicate that the longer the period of residence in the city of Kraków, the stronger the regret about leaving the place of residence. The influence of the burning dimension on the grief is negative, but there is a positive influence of the interaction of the burning dimension and the duration of dwelling in the city on the grief about leaving the place of residence (Figure 3).

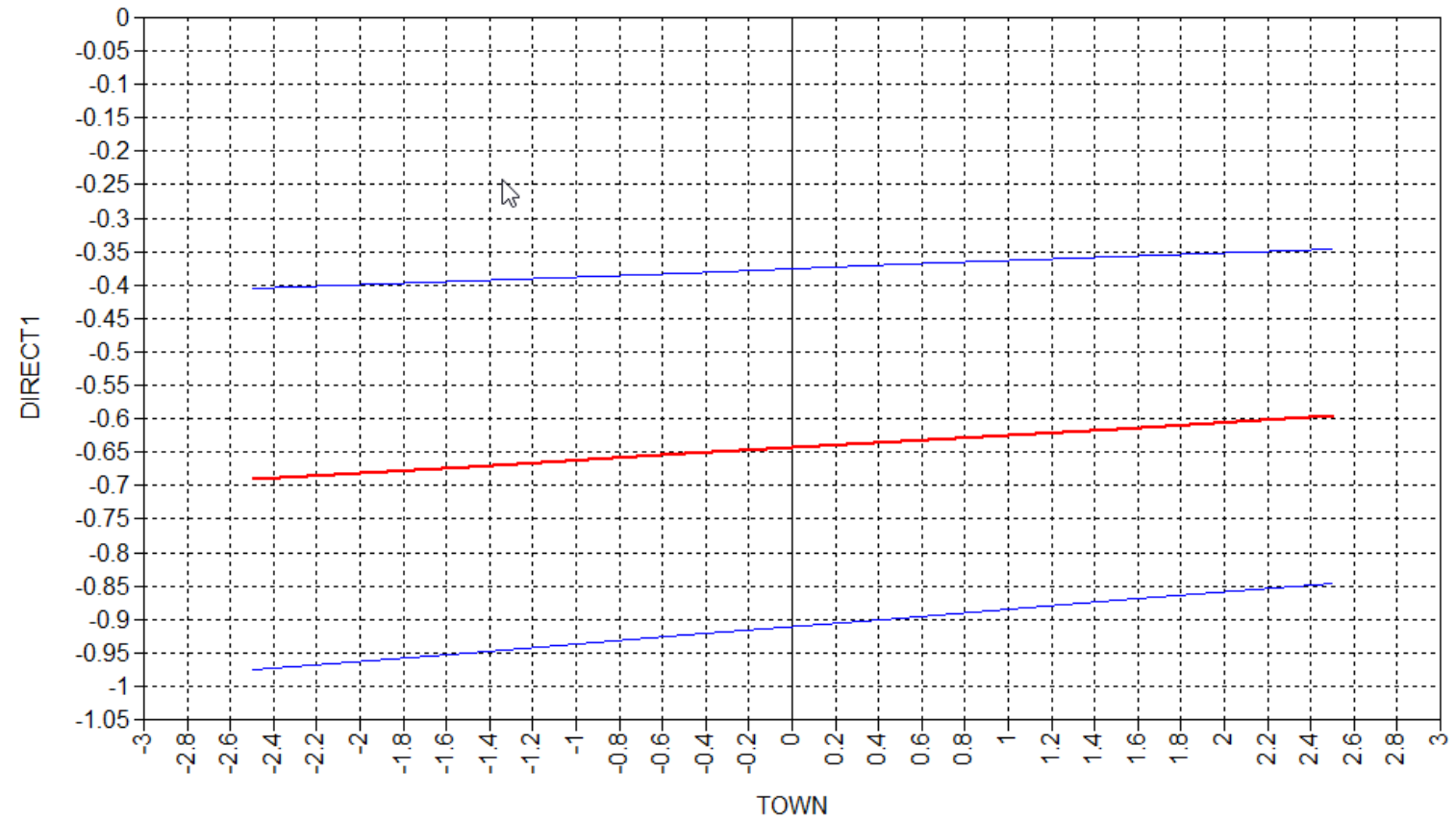

Figure 3. Effect of the interaction between grief and scent dimensions, taking into account the moderation effect in the cross-section of life expectancy in the city.

The graph shows that the lower and upper confidence limits of the parameter do not contain the zero value of the moderation effect. It is claimed that there is a positive interaction effect-with the increase in the number of years of living in the city, there is a stronger positive effect of the combustion dimension on the grief about leaving the place of residence.

The fourth model concerns the relationship between grief and smell dimensions, taking into account the moderation effect in the cross-section of life expectancy in the place of residence (Table 14). 
Table 14. Relationship between grief and smell dimensions, taking into account the moderation effect in the cross-section of life expectancy in the place of residence.

\begin{tabular}{ccccc}
\hline Parameters & Estimate & S.E. & Est/S.E. & $p$-Value \\
\hline Regret on Place & 0.005 & 0.002 & 3.083 & $0.002^{*}$ \\
Regret on Burning & -0.275 & 0.105 & -2.614 & $0.009^{*}$ \\
Regret on Irritating & 0.047 & 0.124 & 0.378 & 0.706 \\
Regret on Smoke & 0.121 & 0.155 & 0.877 & 0.019 \\
Regret on Burning x Place & 0.010 & 0.005 & 2.154 & $0.031^{*}$ \\
Regret on Irritating x Place & -0.005 & 0.007 & -0.788 & 0.431 \\
Regret on Smoke x Place & 0.004 & 0.006 & 0.719 & 0.472 \\
Residual Regret & 0.989 & 0.035 & 28.133 & $0.000^{*}$ \\
\hline
\end{tabular}

* parameters significant at $\alpha<0.05$. The $\mathrm{R}^{2}$ for this model equals 0.01 .

The parameters of the model indicate that the longer the period of residence in the housing estate, the stronger the grief felt over domicile relocation. The influence of the size of burning for grief is negative, but there is a positive influence of the interaction of the size of burning and the length of living in the housing estate on the grief felt over domicile relocation (Figure 4).

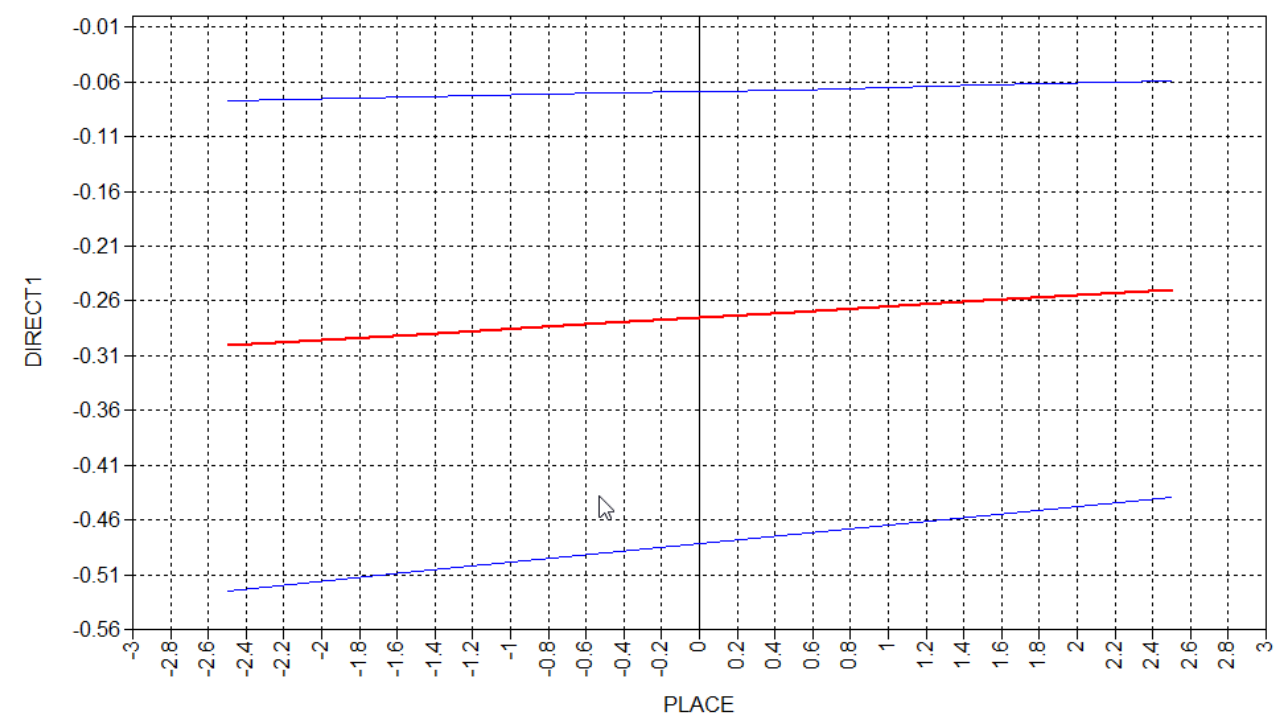

Figure 4. Effect of the interaction between grief and smell, taking into account the effect of moderation in the cross-section of life expectancy in the place of residence.

The graph shows that the upper and lower confidence limits of a parameter do not contain a zero moderation effect value. It is claimed that there is a positive interaction effect-with the increase in the number of years of living in the housing estate, there is a stronger positive effect of the combustion dimension on the grief felt over domicile relocation.

The fifth model concerns the relationship between grief and odor dimensions, taking into account the moderation effect in the cross-section of the life expectancy of the current domicile (Table 15).

The parameters of the model indicate that the duration of dwelling does not significantly influence the regret about leaving the place of residence. The influence of the burning (combustion) dimension on grief is negative, but there is a positive influence of the interaction of the burning dimension and duration of dwelling on the grief felt over domicile relocation (Figure 5). 
Table 15. Relationship between grief and odor dimensions, taking into account the moderation effect in the life expectancy cross-section of the current domicile.

\begin{tabular}{ccccc}
\hline Parameters & Estimate & S.E. & Est/S.E. & $p$-Value \\
\hline Regret on Home & 0.002 & 0.002 & 1.139 & 0.255 \\
Regret on Burning & -0.330 & 0.102 & -3.243 & $0.001^{*}$ \\
Regret on Irritating & -0.029 & 0.120 & -0.237 & 0.812 \\
Regret on Smoke & 0.092 & 0.117 & 0.791 & 0.429 \\
Regret on Burning x Home & 0.017 & 0.006 & 3.134 & $0.002^{*}$ \\
Regret on Irritating x Home & 0.001 & 0.009 & 0.129 & 0.897 \\
Regret on Smoke x Home & -0.001 & 0.007 & -0.131 & 0.896 \\
Residual Regret & 0.991 & 0.035 & 28.133 & $0.000 *$ \\
\hline
\end{tabular}

* parameters significant at $\alpha<0.05$. The $\mathrm{R}^{2}$ for this model equals 0.009 .

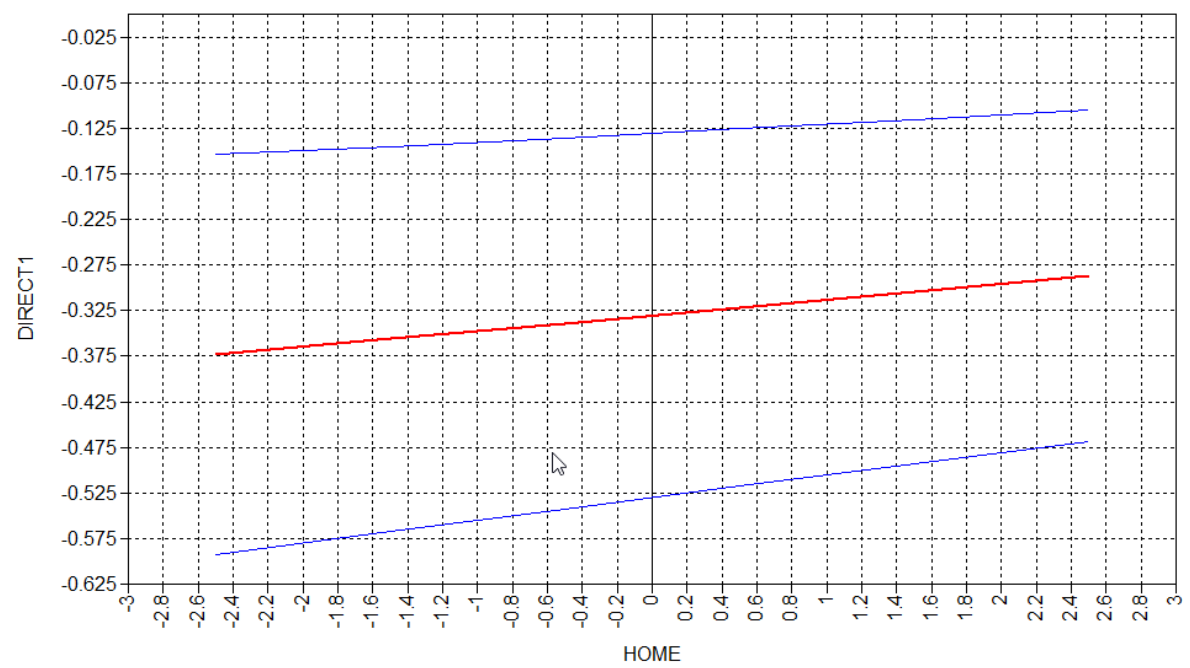

Figure 5. Effect of the interaction of the relationship between the regret and the dimensions of the smell, taking into account the moderation effect in the cross-section of the life expectancy of the current domicile.

The graph shows that the lower and upper confidence limits of the parameter do not contain the zero value of the moderation effect. It is claimed that there is a positive interaction effect-with the increase in the number of years of living in the apartment, there is a stronger positive effect of the combustion dimension on the grief felt over domicile relocation.

\section{Conclusions}

Air quality is an important factor in assessing the quality of life in large cities. It results from the influence of various independent causes, including cyclical climate changes, but also those resulting from the emission of various compounds to the atmosphere-including unpleasant and burdensome smells. Quality of life in urban space is more and more often a problem that determines, to a large extent, the decision on the acceptance of the current place of residence and is the subject of assessment in the context of its possible change. The data obtained as a result of the research allow us to state that specific smells are so burdensome that they may cause the necessity to leave the place of residence because the respondents feel various unpleasant smells that have an adverse impact upon the quality of life that they perceive. A possible need for domicile relocation out of the current place of residence due to unpleasant smells would affect the perceptible, specific level of grief-the more attached the residents are to their current place of residence, the greater it is. According to the respondents, the smell of septic tanks is a noticeable and troublesome one. The regret resulting from a possible domicile relocation correlates significantly and positively with such smell. The more often it is complained about, the greater the regret about a possible domicile relocation, which correlates significantly and 
negatively with the smells described as decay. The more often such smells are complained about, the less regret about a possible domicile relocation there will be.

Studies have confirmed that the smell of burning reduced the regret of leaving the apartment due to the oppressive smell, and the amount of smoke added to the sadness of leaving the apartment. Among men, no dimension significantly affected the regret of leaving the apartment. It has been shown that the longer the period of stay in the city of Krakow, the stronger the regret of leaving the place of residence is, and also that there is a positive interaction effect-with the increase in the number of years of life in the city, the stronger the positive impact of the dimension of burning on the regret of leaving the place of residence becomes. The model parameters indicate that the duration of the apartment does not significantly affect the regret of leaving home. The impact of the burning dimension on grief is negative, but there is a positive impact of the interaction of the smoking dimension and time spent on feeling grief over the relocation.

The practical application of the article has been identified in several areas. The key aspects are the implications for policy makers in the preparation of spatial development plans and regional policy planning. Particular participation in this process will be related to social participation and the role of residents in making decisions about the shape of the region in which they live. Taking into account the voice of residents is the key to determining how to use public space and adapt the city's infrastructure [61]. Controlling industrial emissions of volatile organic compounds is one of the most effective ways to reduce its pollution, which means that cleaner production is an important foundation for reducing odor pollution. Understanding the problem of odors in the environment (including odor origin, odor levels, management of odor sources, cleaner production, and reduction and detection methods) is very important for controlling odor pollution [62]. Currently in Poland, there are no clearly defined methods for measuring odor concentrations for the purpose of assessing the impact of odors on objects. The complex relationship between individual olfactory sensitivity of individuals and the concentration of relevant chemical compounds in the air, their type, and meteorological and topographic conditions affecting the distribution of fragrance leads to numerous disputes and discussions in the scientific community regarding the adoption of an appropriate methodology for measuring offensive odors. Previous studies of odor nuisance are based on chemical methods and electronic noses, which are associated with high cost consumption and difficulty in reaching the measuring site. The conducted tests allow for the initial identification of places with the greatest odor nuisance, which translates into the possibility of detailed tests in selected places.

The Project was financed by the Ministry of Science and Higher Education within the "Regional Initiative of Excellence" Program for 2019-2022. Project no.: 021/RID/2018/19. Total financing: 11,897,131.40 PLN.

Author Contributions: Conceptualization, M.W.; methodology, M.W.; software, A.S.; formal analysis, A.S.; investigation, X.X.; resources, J.P. and G.P.; data curation, J.S.; writing-original draft preparation, M.S.; J.P. and G.P.; writing-review and editing, M.S.; visualization, A.S. and J.P.; project administration, M.W.; funding acquisition, M.S. All authors have read and agreed to the published version of the manuscript.

Funding: Ministry of Science and Higher Education within the "Regional Initiative of Excellence" Program for 2019-2022. Project no.: 021/RID/2018/19.

Conflicts of Interest: The authors declare no conflict of interest.

\section{References}

1. Hoffmann, B. Scent in science and culture. Hist. Hum. Sci. 2013, 26, 31-47. [CrossRef]

2. Marsousin, N.; Khodadadi, R. The Role of Social Capitals in Urban Development with the Emphasis on Life Quality (Case Study: Zanjan City); University of Isfahan: Isfahan, Iran, 2015.

3. Okulicz-Kozaryn, A.; Valente, R.R. Livability and subjective well-being across European cities. Appl. Res. Qual. Life 2018, 14, 197-220. [CrossRef]

4. Buettner, A. (Ed.) Springer Handbook of Odour; Springer: Berlin, Germany, 2017. 
5. Croy, I.; Nordin, S.; Hummel, T. Olfactory disorders and quality of life-An updated review. Chem. Senses 2014, 39, 185-194. [CrossRef] [PubMed]

6. Zucco, G.M.; Schaal, B.; Olsson, M.; Croy, I. Applied olfactory cognition. Front. Psychol. 2014, 5, 873. [CrossRef] [PubMed]

7. Greenberg, M.I.; Curtis, J.A.; Vearrier, D. The perception of odor is not a surrogate marker for chemical exposure: A review of factors influencing human odor perception. Clin. Toxicol. 2013, 51, 70-76. [CrossRef] [PubMed]

8. Alobid, I.; Nogué, S.; Izquierdo-Dominguez, A.; Centellas, S.; Bernal-Sprekelsen, M.; Mullol, J. Multiple chemical sensitivity worsens quality of life and cognitive and sensorial features of sense of smell. Eur. Arch. Oto-Rhino-Laryngol. 2014, 271, 3203-3208. [CrossRef]

9. De Wijk, R.A.; Cain, W.S. Short note odor identification by name and by edibility: Life-span development and safety. Hum. Factors J. Hum. Factors Erg. Soc. 1994, 36, 182-187. [CrossRef]

10. Călămar, A.-N.; Toth, L.; Găman, G.-A.; Kovacs, M. Analysis of olfactive disconfort, generated by industrial activities neighboring residential areas, affecting the quality of life and health of population. In Proceedings of the International Multidisciplinary Scientific GeoConference SGEM, Albena, Bulgaria, 9-30 July 2018; Volume 18, pp. 35-42.

11. Eusebio, L.; Derudi, M.; Capelli, L.; Nano, G.; Sironi, S. Assessment of the indoor odour impact in a naturally ventilated room. Sensors 2017, 17, 778. [CrossRef]

12. Heisterberg, M.V.; Menné, T.; Johansen, J.D. Fragrance allergy and quality of life-A case-control study. Contact Dermat. 2014, 70, 81-89. [CrossRef]

13. Oiamo, T.H.; Luginaah, I.N.; Baxter, J. Cumulative effects of noise and odour nuisances on environmental and health related quality of life. Soc. Sci. Med. 2015, 146, 191-203. [CrossRef]

14. Ternesten-Hasséus, E.; Löwhagen, O.; Millqvist, E. Quality of life and capsaicin sensitivity in patients with airway symptoms induced by chemicals and scents: A longitudinal study. Environ. Health Perspect. 2006, 115, 425-429. [CrossRef] [PubMed]

15. Wolkoff, P. Indoor air humidity, air quality, and health-An overview. Int. J. Hyg. Environ. Health 2018, 221, 376-390. [CrossRef] [PubMed]

16. Brown, R.E. Mammalian social odors: A critical review. Adv. Study Behav. 1979, 10, 103-162.

17. Touhara, K. Odor and pheromone molecules, receptors, and behavioral responses. In The Olfactory System; Springer: Tokyo, Japan, 2014; pp. 19-38. [CrossRef]

18. Weiss, T.; Secundo, L.; Sobel, N. Human olfaction: A typical yet special mammalian olfactory system. In The Olfactory System; Springer: Tokyo, Japan, 2014; pp. 177-202. [CrossRef]

19. Li, R.Y.M.; Li, H.C.Y. Have housing prices gone with the smelly wind? Big data analysis on landfill in Hong Kong. Sustainability 2018, 10, 341. [CrossRef]

20. Van Leeuwen, E.; Vreeker, R.; Rodenburg, C.A. A framework for quality of life assessment of urban green areas in Europe: An application to district park reudnitz Leipzig. Int. J. Environ. Technol. Manag. 2006, 6, 111-122. [CrossRef]

21. Sharida, A.; Hamdan, A.; Al-Hashimi, M. Smart cities: The next urban evolution in delivering a better quality of life. Appl. Hybrid Metaheuristic Algorithms Image Process. 2019, 846, 287-298.

22. Roukouni, A.; Macharis, C.; Basbas, S.; Stephanis, B.; Mintsis, G. Financing urban transportation infrastructure in a multi-actors environment: The role of value capture. Eur. Transp. Res. Rev. 2018, 10, 14. [CrossRef]

23. Cilliers, E.J.; Timmermans, W.; Goorbergh, F.V.D.; Slijkhuis, J.S.A. The story behind the place: Creating urban spaces that enhance quality of life. Appl. Res. Qual. Life 2014, 10, 589-598. [CrossRef]

24. Eltarkawe, M.; Miller, S.L. Industrial odor source identification based on wind direction and social participation. Int. J. Environ. Res. Public Health 2019, 16, 1242. [CrossRef]

25. Eltarkawe, M.A.; Miller, S.L. The impact of industrial odors on the subjective well-being of communities in Colorado. Int. J. Environ. Res. Public Health 2018, 15, 1091. [CrossRef]

26. Brattoli, M.; Mazzone, A.; Giua, R.; Assennato, G.; De Gennaro, G. Automated collection of real-time alerts of citizens as a useful tool to continuously monitor malodorous emissions. Int. J. Environ. Res. Public Health 2016, 13, 263. [CrossRef] [PubMed]

27. Shanahan, L.K.A.; Gottfried, J. Olfactory insights into sleep-dependent learning and memory. Prog. Brain Res. 2014, 208, 309-343. 
28. Cowart, B.J. Relationships between taste and smell across the adult life span. Ann. N. Y. Acad. Sci. 1989, 561, 39-55. [CrossRef]

29. Mitchell, D.J.; Kahn, B.E.; Knasko, S.C. There's something in the air: Effects of congruent or incongruent ambient odor on consumer decision making. J. Consum. Res. 1995, 22, 229-238. [CrossRef]

30. Wu, Y.; Lin, H.; Yin, W.; Shao, S.; Lv, S.; Hu, Y. Water Quality and Microbial Community Changes in an Urban River after Micro-Nano Bubble Technology in Situ Treatment. Water 2019, 11, 66. [CrossRef]

31. Wypych, G. Front matter. In Handbook of Odors in Plastic Materials, 2nd ed.; Elsevier: Amsterdam, The Netherlands, 2017.

32. Byliński, H.; Gębicki, J.; Namiesnik, J. Evaluation of health hazard due to emission of volatile organic compounds from various processing units of wastewater treatment plant. Int. J. Environ. Res. Public Health 2019, 16, 1712. [CrossRef]

33. Nicell, J. Assessment and regulation of odour impacts. Atmos. Environ. 2009, 43, 196-206. [CrossRef]

34. Blanes-Vidal, V.; Nadimi, E.S.; Ellermann, T.; Andersen, H.V.; Løfstrøm, P. Perceived annoyance from environmental odors and association with atmospheric ammonia levels in non-urban residential communities: A cross-sectional study. Environ. Health 2012, 11, 27. [CrossRef]

35. Di Gilio, A.; Palmisani, J.; Petraccone, S.; de Gennaro, G.; Fornaro, A. An intergrated high temporal resolution approach to monitor VOCs ceoncentrations and odour nuisance near pertroleum plant. Environ. Eng. Manag. J. 2018, 17, 2373-2378. [CrossRef]

36. Gou, Z.; Lau, S.-Y.S.; Lin, P. Understanding domestic air-conditioning use behaviours: Disciplined body and frugal life. Habitat Int. 2017, 60, 50-57. [CrossRef]

37. Mirabelli, M.C.; Wing, S.; Marshall, S.; Wilcosky, T.C. Race, poverty, and potential exposure of middle-school students to air emissions from confined swine feeding operations. Environ. Health Perspect. 2006, 114, 591-596. [CrossRef] [PubMed]

38. Muižniece-Treija, E. The research of odour concentration and analysis of air pollutants in Riga. In International Scientific Conference of Daugavpils University; Starptautiskas Zinatniskas Konferences Materiali; Daugavpils Universitates: Daugavpils, Latvia, 2017; Volume 59, pp. 11-20.

39. Wing, S.R.; Horton, R.A.; Marshall, S.W.; Thu, K.; Tajik, M.; Schinasi, L.; Schiffman, S.S. Air pollution and odour in communities near industrial swine operations. Environ. Health Perspect. 2008, 116, 1362-1368. [CrossRef] [PubMed]

40. Brennan, B. Odour nuisance. Water Waste Treat. 1993, 36, 30-33.

41. Bruszkiewski, H.; Skorupski, W. Air pollution caused by a concentrated liquid waste treatment plant. Chem. Ekol. Eng. 1999, 10, 979-987.

42. Lewkowska, P.; Cieślik, B.; Dymerski, T.; Konieczka, P.; Namiesnik, J. Characteristics of odors emitted from municipal wastewater treatment plant and methods for their identification and deodorization techniques. Environ. Res. 2016, 151, 573-586. [CrossRef] [PubMed]

43. Aatamila, M.; Verkasalo, P.K.; Korhonen, M.J.; Suominen, A.L.; Hirvonen, M.-R.; Viluksela, M.K.; Nevalainen, A. Odour annoyance and physical symptoms among residents living near waste treatment centers. Environ. Res. 2011, 111, 164-170. [CrossRef]

44. Fang, J.-J.; Yang, N.; Cen, D.-Y.; Shao, L.-M.; He, P. Odor compounds from different sources of landfill: Characterization and source identification. Waste Manag. 2012, 32, 1401-1410. [CrossRef]

45. Vincent, A.; Hobson, J. Odour control. In CIWEM Monographs on Best Practice No. 2, Chartered Institution of Water and Environmental Management; Terence Dalton Publishing: London, UK, 1998.

46. Carrera-Chapela, F.; Donoso-Bravo, A.; Souto, J.A.; Ruiz-Filippi, G. Modeling the odour generation in WWTP: An integrated approach review. Water Air Soil Pollut. 2014, 225, 1932. [CrossRef]

47. Gębicki, J.; Dymerski, T.; Namieśnik, J. Monitoring of odour nuisance from landfill using electronic nose. Chem. Eng. Trans. 2014, 40, 85-90.

48. Sówka, I.; Bezyk, Y.; Grzelka, A.; Miller, U.; Pachurka, Ł. Seasonal odour impact range of selected wastewater treatment plants-Modeling studies using Polish reference model. Water Sci. Technol. 2017, 2017, $422-429$. [CrossRef]

49. Shusterman, D.; Lipscomb, J.; Neutra, R.; Satin, K. Symptom prevalence and odour-worry interaction near hazardous waste sites. Environ. Health Perspect. 1991, 94, 25-30. [PubMed]

50. Luginaah, I.; Taylor, S.M.; Elliott, S.J.; Eyles, J.D. Community reappraisal of the perceived health effects of a petroleum refinery. Soc. Sci. Med. 2002, 55, 47-61. [CrossRef] 
51. Steinheider, B.; Winneke, G.; Schlipkoter, H.W. Somatic and psychological effects of malodour: A case study from a mushroom fertilizer production plant. Staub Reinhalt. Luft 1993, 53, 425-431.

52. Szyłak-Szydłowski, M. Comparison of two types of field olfactometers for assessing odors in laboratory and field tests. Chem. Eng. Trance 2014, 40, 67-72.

53. Capelli, L.; Sironi, S.; Del Rosso, R. Electronic noses for environmental monitoring applications. Sensors 2014, 14, 19979-20007. [CrossRef] [PubMed]

54. Gardner, J.; Bartlett, P.N. A brief history of electronic noses. Sens. Actuators B Chem. 1994, 18, $210-211$. [CrossRef]

55. Guideline, V.D.I. 3883; Part 1, effects and assessment of odours - psychometric assessment of odour annoyance - questionnaires. Düsseldorf Verein Deutscher Ingenieure 1997, 7, 1-60.

56. Cervinka, R.; Neudorfer, E. Odour Control at a Municipal Sewage Collector: Psychological Perspectives; Erwironmental Odour Management: Koln, Germany, 2004; pp. 13-25.

57. Felscher-Suhr, U.; Guski, R.; Schuemer, R. Internationale Standardisierungsbestrebungen zur Erhebung der Lärmbelästigung. Die Entwicklung von international vergleichbaren äquidistanten Lärmbelästigungsskalen. Z. Lärmbekämpf. 2000, 47, 68-70.

58. Fields, J.; De Jong, R.; Gjestland, T.; Flindell, I.; Job, R.; Kurra, S.; Lercher, P.; Vallet, M.; Yano, T.; Guski, R.; et al. Standardized general-purpose noise reaction questions for community noise surveys: Research and a recommendation. J. Sound Vib. 2001, 242, 641-679. [CrossRef]

59. Witz, K.; Hinkle, D.E.; Wiersma, W.; Jurs, S.G. Applied statistics for the behavioral sciences. J. Educ. Stat. 1990, 15, 84. [CrossRef]

60. R: A language and environment for statistical computing. Available online: https://www.gbif.org/zh/tool/ 81287/r-a-language-and-environment-for-statistical-computing (accessed on 14 September 2019).

61. Falcone, P.M.; D'Alisa, G.; Germani, A.R.; Morone, P. When all seemed lost. A social network analysis of the waste-related environmental movement in Campania, Italy. Political Geogr. 2020, 77, 102114. [CrossRef]

62. Hu, R.; Liu, G.; Zhang, H.; Xue, H.; Wang, X.; Lam, P.K.S. Odor pollution due to industrial emission of volatile organic compounds: A case study in Hefei, China. J. Clean. Prod. 2020, 246, 119075. [CrossRef]

(C) 2020 by the authors. Licensee MDPI, Basel, Switzerland. This article is an open access article distributed under the terms and conditions of the Creative Commons Attribution (CC BY) license (http://creativecommons.org/licenses/by/4.0/). 